\title{
The Wireless Acquisition Data System Simulator Design on Automatic Weather Monitoring Station
}

\section{Rancang Bangun Simulator Sistem Data Akuisisi Nirkabel pada Stasiun Pemantau Cuaca Otomatis}

\author{
Siti Aminah ${ }^{1 *}$, Asep Deni Mulyadi ${ }^{1}$, Yuliadi Erdani²
}

\begin{abstract}
The Wireless Acquisition Data System Simulator Design on Automatic Weather Monitoring Station is means of collecting, monitoring, and controlling some long distance subsystems. Automatic weather monitoring station is device for receiving data by a censor in use to gauge some weather parameters. Sensor characteristics are considered to measure several weather parameters. The principles of a system function are it will have to collect data from some subsystems to accommodate in a database, able to control and deliver instructions to the subsystem. The communication system makes the use of radio frequency by means of Frequency Shift Keying (FSK) method through Handy Talky (HT).. The results of the trial suggest that system design has proper functions, the communication process in this system is two-ways communication, the process was fast working in either transmitter mode or receiver mode.
\end{abstract}

\section{Keywords}

Subsystem, Database, Prototype, Frekuensi Shift Keying (FSK), Handy Talky (HT)

\begin{abstract}
Abstrak
Rancang Bangun Simulator Sistem Data Akuisisi Nirkabel pada Stasiun Pemantau Cuaca Otomatis merupakan alat untuk mengumpulkan, memonitoring dan mengontrol beberapa subsistem secara jarak jauh. Stasiun pemantau cuaca otomatis menampung data-data dari sensor yang digunakan untuk mengukur beberapa parameter cuaca. Karakteristik sensor diperhatikan untuk mengukur beberapa parameter cuaca. Prinsip kerja sistem mengumpulkan data dari beberapa subsistem untuk ditampung dalam database, mengontrol dan memberikan perintah kepada subsistem. Sistem komunikasi menggunakan frekuensi radio dengan memanfaatkan metode Frequency Shift Keying (FSK) melalui media Handy Talky (HT). Hasil pengujian menunjukkan sistem yang dirancang telah berfungsi dengan baik, dengan proses komunikasi dua arah dan bekerja pada mode pengirim ataupun mode penerima.
\end{abstract}

\section{Kata Kunci}

Subsistem, Database, Prototype, Frekuensi Shift Keying (FSK), Handy Talky (HT).

\author{
${ }^{1}$ Jurusan Teknik Otomasi Manufaktur dan Mekatronika, Mekatronika POLMAN, Bandung \\ Jl. Kanayakan No.21, Dago, Kecamatan Coblong, Kota Bandung, Jawa Barat 40135 \\ 2 Elektromekanik, Program Studi Teknik Mesin dan Manufaktur, POLMAN, Bandung \\ Jl. Kanayakan No.21, Dago, Kecamatan Coblong, Kota Bandung, Jawa Barat 40135 \\ *aminah@ polman-bandung.ac.id \\ Submitted : August 22, 2019. Accepted : August 29, 2019. Published : September 01, 2019.
}




\section{PENDAHULUAN}

Indonesia merupakan Negara Kepulauan yang beriklim tropis, dengan curah hujan yang cukup tinggi. Keadaan iklim atau kondisi alam menjadi salah satu faktor terpenting dalam kehidupan, dimana kondisi alam digunakan atau dimanfaatkan dalam mendukung aktifitas manusia. Kondisi alam yang paling banyak disorot dalam pemanfaatannya berupa suhu udara, kecepatan angin, arah angin, kelembaban udara, curah hujan dan lain-lain [1].

Sampai saat ini telah dikembangkan penelitian mengenai Automatic Weather Station (AWS) [2] dengan parameter cuaca yang diukur yaitu berupa curah hujan, suhu dan kelembaban. Sistem pengiriman data atau komunikasi data antara PC dengan mikrokontroller yaitu menggunakan serial sehingga pada saat pengambilan data ke PC, PC harus berada dekat dengan plant atau alat. Penampilan data saat ini menggunakan visual basic. Perancangan sistem telemetri telah dirancang oleh Mashaler Suradam [3] yaitu membuat alat untuk mengukur beberapa parameter seperti tekanan dengan BMP085, DHT22 untuk sensor kelembaban dan temperatur. Data yang dihasilkan dari pembaca sensor dikirimkan serta divisualisasikan dan disimpan pada Weather Base Station (WBS).

Berdasarkan keadaan alat AWS sekarang, alat tersebut dapat dinilai kurang efisien jika digunakan dilapangan terutama apabila digunakan untuk penelitian di daerah-daerah terpencil atau remote area dikarenakan peneliti harus berada dekat dengan plant atau alat. Oleh karena itu untuk menjawab permasalahan diatas, maka diperlukan pengembangan alat untuk memonitoring dan mengumpulkan kondisi alam dalam hal ini cuaca dengan akses komunikasi data jarak jauh atau nirkabel. Akses jarak jauh atau nirkabel dimaksudkan agar peneliti dapat memonitoring kondisi alam tepat diposisi aman, jika posisi plant ditempatkan didaerah rawan.

Monitoring dan pengkontrolan jarak jauh semakin meningkat dari tahun ketahun, sejalan dengan perkembangan peradabaan manusia yang tak lagi mengenal batas dan jarak sehingga menuntut sebuah sistem yang cerdas, efesien, informatif, dan fungsional sehingga dapat mempermudah hidup manusia. Sehingga terciptalah sebuah sistem kontrol dan monitoring jarak jauh yang memanfaatkan mikrokontroler dikarenakan biayanya murah dan luas pemanfaatannya, Nurahmadi dan Ashari telah mengembangkan Sistem Kontrol dan Monitoring suhu jarak jauh dengan memanfaatkan sistem mikroprosesor W5100 dan ATMega 8535 [4].

\section{METODE PENELITIAN}

Metode untuk rancang bangun simulator sistem data akuisisi nirkabel menggunakan VDI 2206 dikenal sebagai V-model, banyak dipakai untuk sistem mekatronik [5]. Tahapan Vmodel dimulai dari requirement (mendefinisikan kebutuhan), System design (mendefinisikan konsep solusi ), domain specific design (Konsep solusi dirancang secara detail), System integration (integrasi dari hasil setiap domain), Verification/Validation (memastikan hasil desain sesuai dengan kebutuhan), modelling and model analysis (memodelkan sistem), dan product (produk yang dihasilkan) [5], V- model ditunjukkan Gambar 1.

\section{Konsep Weather Station}

Weather Station adalah sebuah fasilitas dengan peralatan yang digunakan untuk mengamati kondisi atmosfer untuk memberikan informasi prakiraan cuaca atau penelitian tentang cuaca dan iklim [6]. Pendapat lain menyatakan Automatic weather station adalah serangkaian sensor-sensor meteorologi yang disusun secara terpadu dan secara otomatis mencatat data-data meteorologi (suhu, tekanan, kelembaban, penyinaran matahari, curah hujan, angin) yang kemudian menghasilkan pulsa-pulsa elektrik yang akan ditampung dan diubah dalam data logger sehingga dapat ditampilkan pada layar komputer atau translator [7]. 


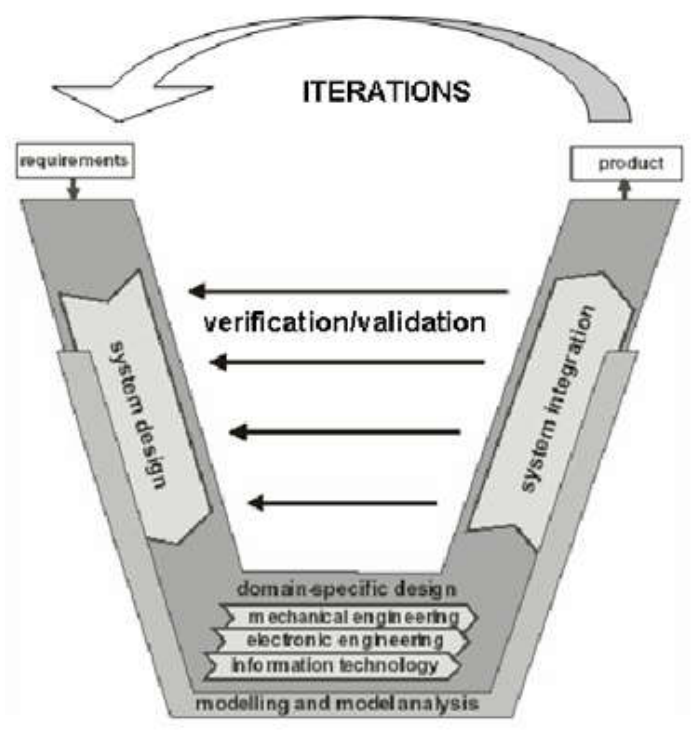

Gambar 1. VDI 2206 [5]

Data akuisisi menurut C.J. Date [8] database adalah koleksi "data operasional" yang tersimpan dan dipakai oleh sistem aplikasi dari suatu organisasi. Sistim akuisisi data menurut F. Rijal [9] didefinisikan sebagai suatu sistem yang berfungsi untuk mengambil, mengumpulkan dan menyiapkan data, hingga memprosesnya untuk menghasilkan data yang dikehendaki. Jenis serta metode yang di pilih pada umumnya bertujuan untuk menyederhanakan setiap langkah yang dilaksanakan pada keseluruhan proses. Sistem akuisisi jarak jauh mempunyai komponen pengambil dan pengolah data dengan jarak berjauhan, maka dibutuhkan media untuk mentransfer antara kedua sub sistem tersebut. Kondisi ini membutuhkan sistem memori yang disuplai baterai sebagai penampung sementara, memori seperti ini disebut sistem memori RAMPACK. Data yang diambil disimpan di memori RAMPACK, kemudian memori dibawah ketempat komputer pengolahan data. Sistem lain menggunakan sistem komunikasi, data diambil oleh transduser yang terletak jauh dari komputer kemudian data ditransmisikan melalui saluran komunikasi, bila saluran komunikasi merupakan sistem analog, diperlukan komponen yang disebut modem [9]. Untuk melewatkan data digital pada media transmisi analog diperlukan peralatan yang disebut modem (modulator - demodulator) berfungsi untuk merubah sinyal digital ke analog dan mengembalikan sinyal analog ke bentuk kembali pada sisi penerima [10].

Berdasarkan acuan dari kajian pustaka yang telah dilakukan oleh beberapa peneliti terdahulu yang membuat alat yang hampir sama baik dari segi konsep maupun media yang digunakan, penulis menemukan beberapa celah untuk pengembangan agar sistem dapat berfungsi lebih baik. Beberapa kelemahan seperti proses pengiriman data yang menggunakan komunikasi serial dimana komunikasi tersebut mempunyai jarak yang pendek. Maka dari itu dalam pengerjaan digunakan proses pengiriman data secara nirkabel dengan tujuan komunikasi data dapat dilakukan dengan jarak jauh. Media yang digunakan dalam komunikasi nirkabel banyak macamnya seperti satelit, akses provider, frekuensi radio, bluetooth, infrared dan lain-lain. Pemilihan penggunaan media komunikasi ini sangatlah penting dan harus disesuaikan dengan kebutuhan. Pada penelitian dibutuhkan jarak yang cukup jauh jadi tidak memungkinkan untuk menggunakan bluetooth dan infrared. Selain itu juga tidak memungkinkan untuk menggunakan akses provider dikarenakan komunikasi pada akses provider bisa terputus apabila terjadi bencana seperti ditunjukkan pada gambar 2 . 


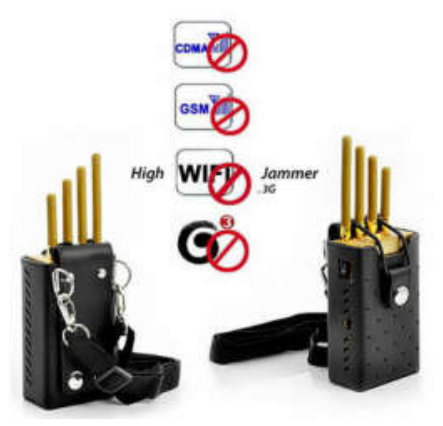

Gambar 2. Akses Provider Terputus saat Bencana

Berdasarkan penelitian-penelitian yang menyebutkan mengenai kelemahan dan kelebihan dari media yang ada maka pada penelitian ini menggunakan media frekeunsi radio dengan piranti Handy Talky (HT). Pada penelitian ini dibuatkan kerangka subsistem untuk pengujian sistem. Subsistem yang dibuat ini digunakan dengan menghubungkan ke sensorsensor yang digunakan untuk mengukur parameter-parameter cuaca. Gambar 3 dibawah ini merupakan gambar perancangan subsistem yang dibuat pada penelitian ini.

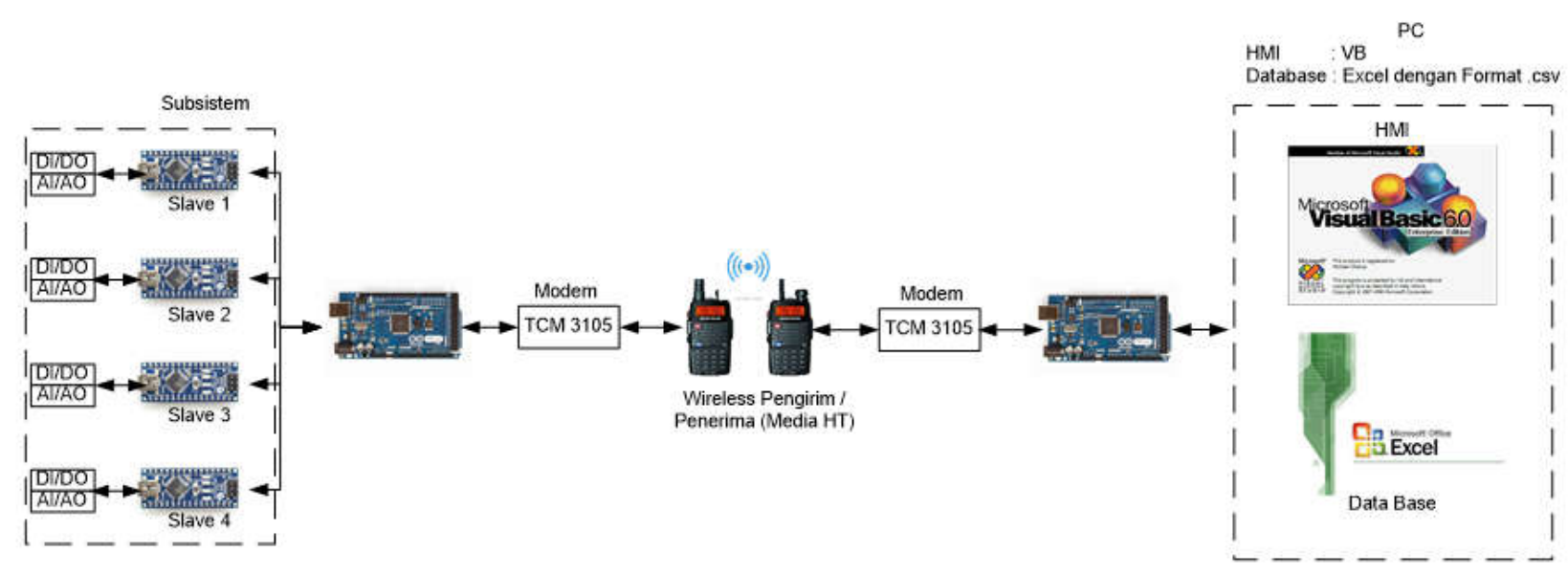

Gambar 3 Arsitektur Simulator Sistem Stasiun Pemantau Cuaca Otomatis

Berdasarkan gambar 3, sistem dituntut untuk dapat berkomunikasi secara dua arah, dimana sistem ini mendapat data dari empat buah subsistem yang ada. Subsistem-subsistem yang ada mengirimkan data secara terus menerus dengan interval waktu yang telah ditentukan. Subsistem-subsistem yang dibuat pada penelitian diwakili dengan Pin Digital dan Pin Analog yang ada pada mikrokontroler. Penggunaan Pin Digital dan Pin Analog ini berdasarkan penjabaran dari alat-alat yang digunakan pada pemantauan cuaca seperti ditunjukkan pada gambar 4. 


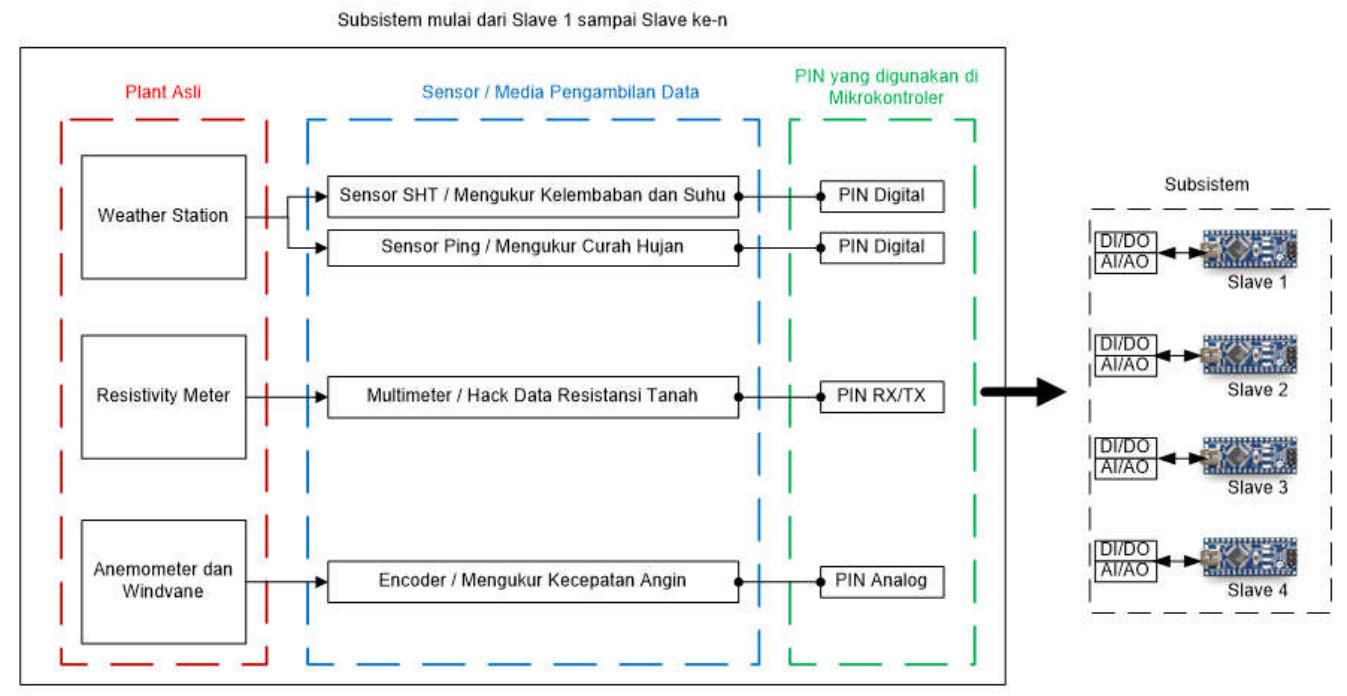

Gambar 4 Penjabaran Subsistem Pemantau Cuaca

Pada penjabaran subsistem yang ada pada gambar 4 dapat diketahui bahwa masingmasing peralatan yang digunakan pada stasiun pemantau cuaca seperti weather station, anemometer, resistivity meter dimana masing-masing sensor yang digunakan itu mempunyai karakteristik yaitu memanfaatkan Pin Digital dan Pin Analog mikrokontroler untuk mengukur parameter-parameter cuaca.

\section{Perancangan Sistem}

Secara umum sistem yang dibuat seperti ditunjukkan gambar 2 dimana sistem dapat bekerja secara dua arah dengan mikrokontroler sebagai elemen utama, mikrokontroler yang digunakan yaitu Arduino dengan jenis Arduino Mega dan Arduino Nano. Mikrokontroler Arduino Mega digunakan sebagai Master, sedangkan Arduino Nano digunakan sebagai Slave. Berikut ini merupakan penjelasan dari alur kerja dari sistem ditunjukkan oleh gambar 5.

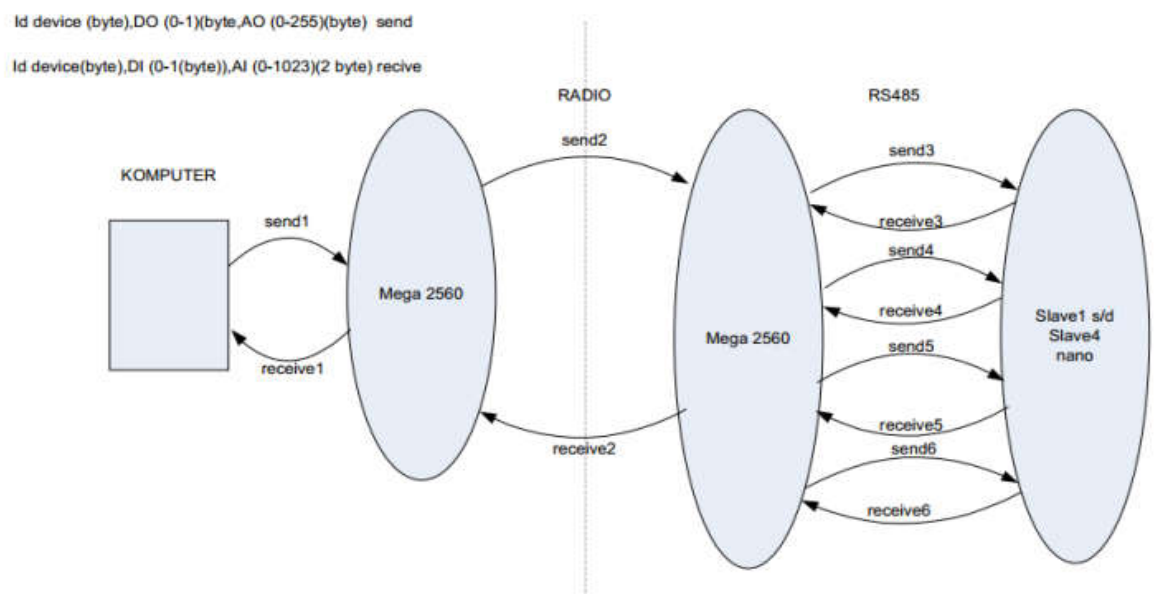

Gambar 5. Diagram Kerja Sistem

Berdasarkan diagram kerja sistem yang ditunjukkan oleh gambar 5 sistem dapat bekerja dalam dua buah mode yaitu mode pengirim dan penerima. Pengaturan pengubahan mode pengirim dan penerima sekaligus pengiriman data dijabarkan dalam flowchart yang ditunjukkan pada gambar 6. 


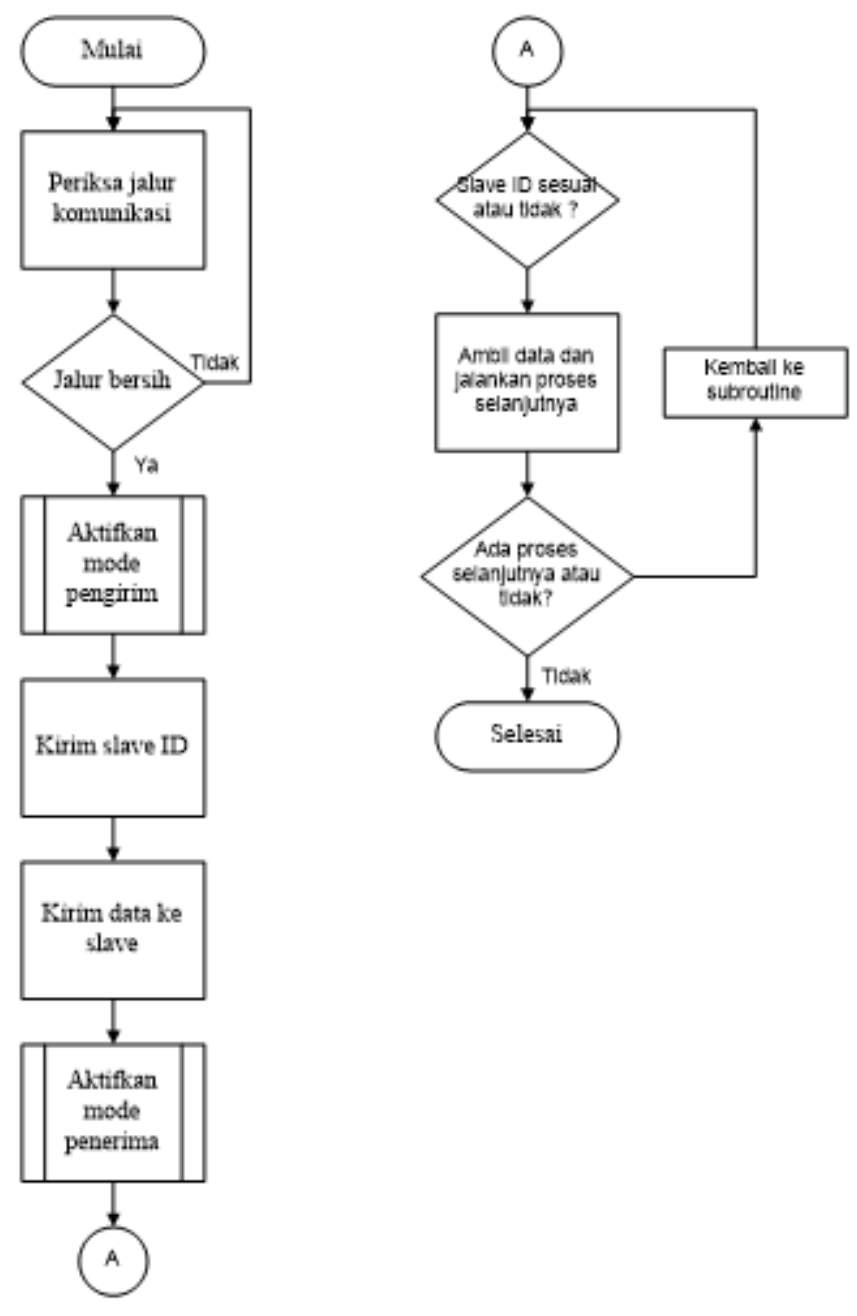

Gambar 6. Flowchart Program

Pada perancangan ini slave atau subsistem dibuat dalam mode pengirim terus-menerus dengan waktu pengiriman selama 3 detik dari masing-masing subsistem. Pembacaan pertama mulai dari subsistem/slave pertama mengirimkan data ke master kemudian melakukan pengiriman data balik ke subsistem berupa status data pengiriman dan selanjutnya berpindah ke subsistem/slave yang selanjutnya dengan proses yang sama sampai dengan subsistem atau slave yang terakhir. Setelah semua subsistem/slave mengirimkan data dan proses pengiriman data balik berupa status telah selesai dilakukan maka data ditampung dimaster sesuai dengan nomer subsistem/slave yang telah diinisialisasi atau dikenal dengan istilah paket data. Data yang telah diterima dan sudah dalam bentuk paket kemudian dikirim melalui media Handy Talky sebelum dikirim data di modulasi terlebih dahulu agar handy talky dapat mengenal sinyal yang akan dikirimkannya. Setelah data dikirim, sebelum masuk ke master yang berikutnya maka data di demodulasi terlebih dahulu agar data dapat terbaca oleh mikrokontroller. Data selanjutnya dapat dibaca di PC ditampilkan dan direcord. Selain itu juga pada perancangan ini sistem dapat memberikan perintah untuk mengontrol subsistem/slave dengan proses pengiriman data yang hampir sama dengan proses penerimaan data.

Perancangan sistem lainnya yaitu perancangan sistem elektronik dimana pada perancangan sistem elektronik terdapat dua buah perancangan yang pertama perancangan rangkaian TCM3105 yang memanfaatkan teknik Modulasi dan Demodulasi dengan metode 
Frekuensi Shift Keying dan buka tutup jalur komunikasi data yang dilakukan oleh Push to Talk. Rancangan skematik ditunjukkan oleh gambar 7.

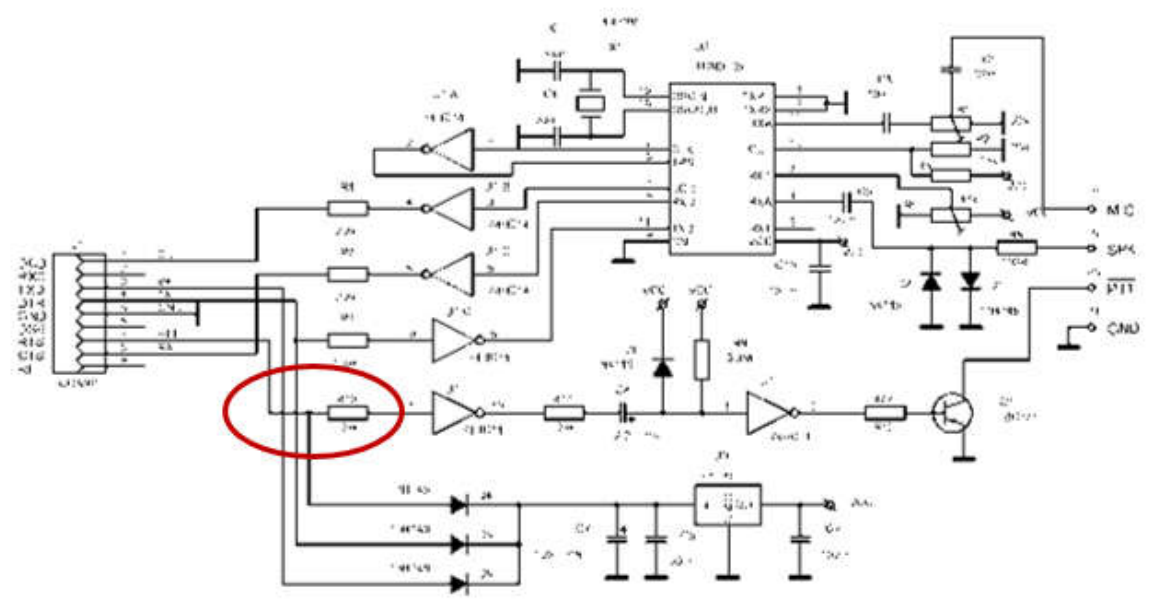

Gambar 7. Skematik Perancangan Rangkaian TCM3105

Pada skematik yang ditunjukkan gambar 7 terdapat dua buah fungsi dari rangkaian ini yang pertama yaitu pengaturan jalur komunikasi, dimana pengaturan ini dimaksudkan untuk mengubah mode baik menjadi penerima atau pengirim. Pengaturan dilakukan dengan menggunakan transistor yang difungsikan sebagai switching dengan menghubungkan ke Push to Talk dari HT, pembacaan data memanfaatkan jalur mic dan speaker dari HT. Sedangkan fungsi yang kedua yaitu digunakan untuk Modulasi dan Demodulasi sinyal. Teknik Modulasi dan Demodulasi diperlukan dikarenakan HT hanya dapat menerima data dalam bentuk sinyal analog sedangkan sensor dan mikrokontroler bekerja dalam bentuk sinyal digital. Oleh karena itu pada saat data diterima dan dikirim harus diubah terlebih dahulu. Modulasi yaitu mengubah data dari sinyal digital menjadi sinyal analog, sedangkan Demodulasi yaitu mengubah sinyal analog menjadi sinyal digital [10].

Pada perancangan sistem elektronik yang merupakan perancangan rangkaian kedua yaitu perancangan RS485 yang berfungsi untuk komunikasi data one to many atau multipoint. Berikut ini merupakan peracangan dari rangkain RS485 dengan menggunakan IC SN75176 ditunjukkan pada gambar 8.

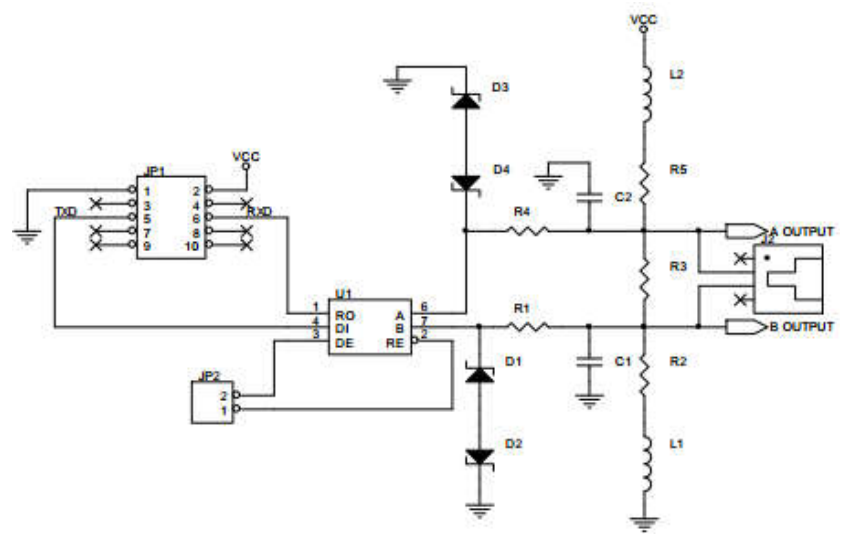

Gambar 8. Skematik SN75176 untuk Komunikasi Multipoint / One to Many

Pada komunikasi RS485, semua peralatan elektronik berada pada posisi penerima hingga salah satu memerlukan untuk mengirimkan data, maka peralatan tersebut akan berpindah ke 
mode pengirim, mengirimkan data dan kembali ke mode penerima. Setiap kali peralatan elektronik tersebut hendak mengirimkan data, maka terlebih dahulu harus diperiksa, apakah jalur yang digunakan sebagai media pengiriman data tersebut tidak sibuk. Apabila jalur masih sibuk, maka peralatan tersebut harus menunggu hingga jalur sepi.

\section{HASIL DAN PEMBAHASAN}

Sistem pengiriman dan penerimaan dilakukan secara nirkabel dengan tujuan mendapatkan jarak pengiriman yang jauh agar sistem dapat disimpan di remote area sekalipun ditempat yang ekstrim, gambar 9 menunjukkan hasil implementasi.

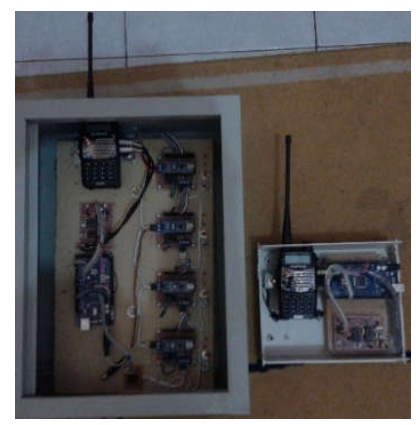

Gambar 9. Implementasi Hasil Perancangan

Berdasarkan hasil implementasi yang telah dilakukan, tahap selanjutnya dilakukan pengujian untuk membuktikan fungsi dari sistem. Berikut ini merupakan beberapa pengujian yang dilakukan yaitu:

\section{Pengujian Domain Mekanik}

Pada pengujian domain mekanik ini hanya dilakukan beberapa penyesuaian tata letak komponen agar penggunan dapat digunakan semudah mungkin. Prosedur yang dilakukan yaitu:

1. Pengecekan tata letak penempatan komponen.

2. Pengecekan fungsi dari sistem.

Berdasarkan prosedur pengujian yang telah dijabarkan maka dilakukan pengujian yang mana didapatkan hasil bahwa sistem berjalan dan berfungsi dengan baik, ditunjukkan oleh gambar 10.

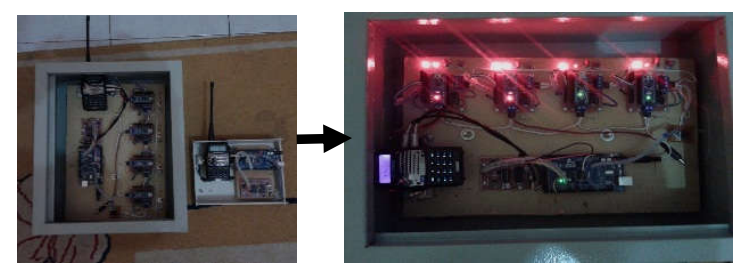

Gambar 10 Pengujian Domain Mekanik

\section{Pengujian Domain Elektronik}

Pada pengujian domain elektronik lebih ditekankan pada pengujian rangkaian-rangkaian elektronik yang digunakan. Prosedur yang dilakukan yaitu:

1. Pengecekan jalur supply dan kesesuaian supply terhadap beban yang digunakan.

2. Pengecekan fungsi dari rangkaian Modem.

3. Pengecekan rangkaian RS485.

Berdasarkan prosedur pengujian yang ada pada domain elektronik, dilakukan beberapa pengujian. Pengujian yang pertama adalah pengujian jalur supply pengujian ini dilakukan 
dengan mengecek tegangan yang masuk pada masing-masing input dan output dari setiap komponen utama. Berikut merupakan tabel hasil pengecekan tegangan dengan menggunakan multimeter ditunjukkan pada tabel 1.

Tabel 1 Hasil Pengecekan Tegangan

\begin{tabular}{|c|c|c|}
\hline Kebutuhan Supply & Input & Output setelah ditambah beban \\
\hline 12 volt & 11,8 volt & 10,9 volt \\
\hline 5 volt & 5 volt & 4,8 volt \\
\hline
\end{tabular}

Berdasarkan hasil yang didapat pada proses pengukuran maka didapatkan perhitungan analisa sebagai berikut:

1. Kebutuhan supply $12 \mathrm{~V}$ pada input $=\frac{11.8}{12} \times 100 \%=98.3 \%$

2. Kebutuhan supply $12 \mathrm{~V}$ pada bagian output $=\frac{10.9}{12} \times 100 \%=90.83 \%$

3. Kebutuhan supply $5 \mathrm{~V}$ pada bagian input $=\frac{5}{5} \times 100 \%=100 \%$

4. Kebutuhan supply $5 \mathrm{~V}$ pada bagian output $=\frac{4.8}{5} \times 100 \%=96 \%$

Berdasarkan hasil tersebut maka analisa untuk kebutuhan supply dapat dikatakan berfungsi dengan baik karena dengan error dibawah $10 \%$ beban masih dapat menyala. Tujuan pengecekan ini adalah untuk antisipasi kebutuhan supply masih mampu atau tidak untuk mengaktifkan komponen utama dengan batas minimum kebutuhan supply yang dimilikinya.

Pengujian yang kedua adalah pengujian rangkaian Modem dan RS485, pengujian dilakukan dengan dua tahapan. Pertama yaitu dengan menyambungkan output ke speaker. Pengujian dilakukan untuk mengecek terjadi atau tidaknya proses terima dan kirim data, pengujian ditunjukkan pada tabel 2 dibawah ini:

Tabel 2 Hasil Pengecekan Menggunakan Speaker

\begin{tabular}{|c|l|}
\hline Proses & Keterangan \\
\hline Kirim Data & Ada suara \\
\hline Terima Data & Ada suara \\
\hline
\end{tabular}

Berdasarkan hasil pengecekan menggunakan speaker komunikasi dua arah yang dimaksud dapat berjalan dengan lancar dimana pada hasil pengujian dengan menggunakan speaker terdapat suara baik pada saat pengiriman maupun terima data, hal tersebut menunjukkan terjadinya proses terima dan kirim data.

Tahapan yang kedua yaitu mengecek kesesuaian data yang dikirim dan diterima apakah sesuai atau tidak, kesesuaian data yang dimaksud yaitu berupa data yang dikirim datanya valid atau tidak dan sesuai dengan nomor slavenya atau tidak. Maka pengujian pada tahap ini cara pengecekan dilakukan dengan menguji keseluruhan sistem serta menganalisa dari hasil data yang diperoleh dan terekam dalam data akuisisi. Berikut merupakan contoh pengiriman data ditunjukkan gambar 11. 


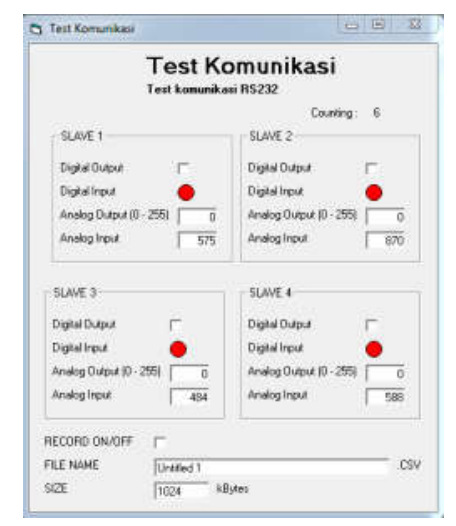

Gambar 11 Contoh Pengiriman dan Penerimaan Data

Pengiriman dan penerimaan data dapat terekam dalam data akuisisi menggunakan Microsoft Excel dengan format file .CSV. Format data yang diterima haruslah berurutan mulai dari Nomor Slave / Slave ID, Data Digital Input, Data Analog Input, ditunjukkan gambar 12 yang merupakan data yang terekam dalam Microsoft Excel.

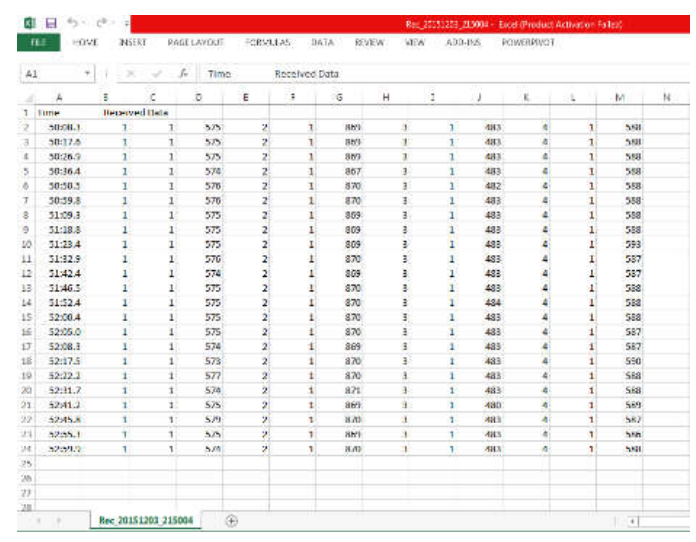

Gambar 12. Data yang Terekam dalam MS.Excel

Berdasarkan data yang terekam maka dapat ditarik kesimpulan untuk proses komunikasi data berjalan dengan lancar, data yang diterima dan dikirim sesuai baik dari nomor slave / slave id, data digital input/output, data analog input/output.

\section{Pengujian Domain Software}

Pengujian pada domain informatik ini lebih ditekankan pada kesesuaian diagram alir program yang telah dirancang pada bab perancangan sistem. Prosedur pengujian pada domain informatik ini yaitu mengecek apa yang terjadi pada sistem, saat sistem melakukan pembacaan data, pengiriman data maupun penerimaan data.

Berdasarkan prosedur pengujian, hal yang dapat diteliti disini adalah kesesuaian diagram alir program dengan hasil yang diperolehnya, dalam hal ini nilai counting, pada diagram alir program nilai counting akan bertambah terus menerus dan sesuai ditunjukkan pada gambar 12.

Pada contoh yang ditunjukkan digambar 13 yang ditandai, dimana nilai counting terkadang naik lebih dari +1 , menurut analisa program hal ini terjadi karena pada program nilai counting terus menerus menambah +1 pada aplikasinya jika tidak ada perubahan data atau time out dalam pembacaan data telah habis maka program terus menerus melakukan 
routine dan data yang tidak ada perubahan atau telah melewati batas time out maka data tidak ditampilkan, hal ini digunakan untuk efisiensi data yang terekam.

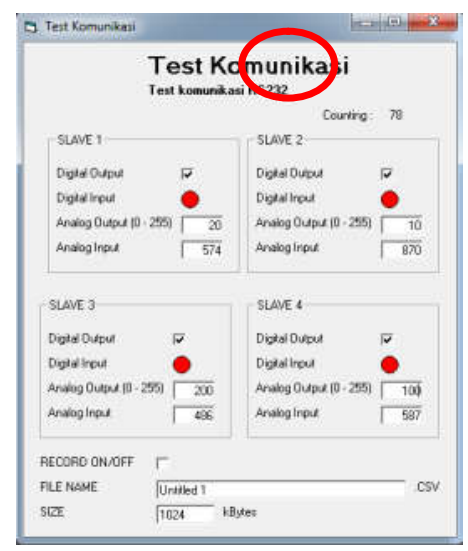

Gambar 13. Contoh Counting

\section{SIMPULAN DAN SARAN}

\section{Simpulan}

Alat Rancang Bangun Simulator Sistem Data Akuisisi Nirkabel pada Stasiun Pemantau Cuaca Otomatis telah dapat dibuat. Alat sudah dapat menerima, mengirim dan mengumpulkan data dari beberapa subsistem bahkan dapat mengontrol subsistem jadi sistem ini dapat berkomunikasi dua arah. Saat ini data yang diterima dan dikirim dari subsistem merupakan prototype dengan konsep yang sama dengan plant asli yang masih dalam tahap penelitian. Jarak komunikasi data kira-kira 1,5 km.

Penampilan data, pengambilan data dan perekaman data sudah dapat dilakukan dengan baik dengan interval waktu 3 detik, apabila tidak ada perubahan data atau pengiriman melebihi interval waktu 3 detik maka data tidak dikirmkan dan program akanroutine untuk pengecekan data selanjutnya.

\section{Saran}

Penelitian lanjutan dapat dilakukan dengan memperhatikan beberapa perbaikan kekurangan yang ada, saran-saran perbaikan dijelaskan berikut ini. Dalam perancangan masih menggunakan data dari subsistem yang merupakan sebuah prototype dengan konsep yang sama, agar lebih real untuk kedepannya apabila plant yang asli sudah selesai dibuat maka dilakukan sinkronisasi untuk pengambilan data dari plant yang sebenarnya. Pengoptimalan jarak maksimal baik dalam pengujian maupun pada aplikasinya dengan menganalisa dari optimalisasi jarak komunikasi data menggunakan handy talky.

\section{DAFTAR RUJUKAN}

[1] Badan Penelitian dan Pengembangan Pertanian - Balingbangtan, 2014, Weather Station, diakses 10 November 2014.

[2] Erdani Y., Amarullah F., 2014, Rancang Bangun Statsiun Pemantauan Cuaca Otomatis dengan Parameter Suhu, Kelembaban dan Kecepatan Angin, STEMAN, POLMAN Bandung, 19-20 September.

[3] Suradam M., 2012, Perancangan Sistem Telemetri Akuisisi Data Cuaca dengan Xbee ProS2, FMIPA Univerisitas Jakarta.

[4] Nurahmadi F., Ashari A., 2011, Sistem Kontrol dan Monitoring Suhu Jarak Jauh Memanfaatkan Embedded System Mikroprosesor W5100 dan ATMega8535, IJEIS Vol.1 No.2, FMIPA UGM, Yogyakarta. 
[5] Gausemeier J., Moehringer S., , 2002, VDI 2206 - A New Guideline for the design of Mechatronic Systems, IFAC Publications, www.elsevier.com/locate/ifac, diakses 25 Oktober 2018.

[6] Yulianto E., Arifin S., Abadi I., 2012, Perancangan Sistem Akuisisi Data pada Mini Maritime Weather Station, ITS, Surabaya.

[7] Datimoria A., 2014, Automatic Weather Station, http://maulina.files.wordpress.com, diakses 10 November 2014.

[8] Date, C.J, 2005, Pengenalan Sistem Basisdata Jilid 2, Indeks, Jakarta.

[9] Rizal F., 2018, Sistem Akuisisi Data, Teknik Elektro Universitas Sumatra Utara, http://habibipte.blogspot.com/p/sistem-akuisisi-data.html, diakses 25 Oktober 2018.

[10] Ardita M., Affandi A., , 2012, Kinerja Modem Adhoc Radio untuk Mendukung Manajemen Transportasi Kapal Tradisional, http://digilib.its.ac.id/public/ITS-Master-10534Paper.pdf, ITS, Surabaya, di akses 10 November 2014.

\section{Biodata Penulis}

Siti Aminah, menyelesaikan pendidikan S2 di Program Studi (PS) Informatika Institut Teknologi Bandung (ITB) pada tahun 2005 dan menyelesaikan S1 PS Teknik Informatika di Sekolah Tinggi Teknologi YBS Internasional pada tahun 2001. Sekarang penulis bekerja sebagai tenaga pengajar di Politeknik Manufaktur Bandung.

Asep Deni Mulyadi, menyelesaikan pendidikan D4 Program Studi Teknik Mesin dan Manufaktur, POLMAN, Bandung.

Yuliadi Erdani, menyelesaikan pendidikan S3 di Universitaet Duisburg-Essen, Germany Program Studi Informationstechnik, S2 di Universitaet Duisburg, Germany, Computer Science and Communication Egineering (CSCE), S1 Ingenieurschule Burgdorf (ISB)/HTA Bern, Teknik Elektro. Sekarang penulis bekerja sebagai tenaga pengajar di Politeknik Manufaktur Bandung. 